\title{
CRISE AMBIENTAL, ENSINO DE BIOLOGIA E EDUCAÇÃO AMBIENTAL Uma abordagem crítica
}

\author{
ENVIRONMENTAL CRISIS, BIOLOGY TEACHING AND ENVIRONMENTAL EDUCATION \\ A critical approach
}

\author{
Adriana Maria Avila, Rodrigo Lingnau
}

1 Pedagoga, Especialista em Teorias e Metodologias da Educação pela UNOCHAPECÓ, Mestranda em Desenvolvimento Regional do PPGDR, Universidade Tecnológica Federal do Paraná - UTFPR, Pato Branco, PR, Brasil.

2 Doutor em Zoologia, Docente do Programa de Pós-Graduação em Desenvolvimento Regional - PPGDR, Universidade Tecnológica Federal do Paraná - UTFPR, Pato Branco, PR, Brasil.

\section{Resumo}

Em meio ao cenário delineado pela problemática ambiental, que se manifesta através da destruição sem precedentes dos recursos naturais, dos altos índices de poluição que vem causando grandes males à saúde humana, a escassez de alimentos, o aumento das desigualdades sociais, entre tantos outros efeitos catastróficos da problemática ambiental; as ciências naturais têm desempenhado um papel importante na conscientização dos efeitos maléficos em determinados comportamentos humanos relacionados ao meio ambiente. Esse artigo objetiva discutir a crise ambiental e seus desdobramentos para desse modo através de uma abordagem crítica compreender o papel da biologia na promoção da Educação Ambiental. Sendo assim, para além do mero ensino de práticas de preservação dos elementos constituintes da flora e da fauna, o ensino de biologia necessita apresentar um caráter de criticidade frente à problemática ambiental possibilitando aos alunos compreender a complexidade da problemática ambiental bem como sua amplitude e seus efeitos globais.

Palavras-chave: Problemática Ambiental. Ensino de Biologia. Educação Ambiental. Abordagem Crítica.

\section{Abstract}

Amid the scenario outlined by the environmental problem, which manifests itself through the unprecedented destruction of natural resources, the high levels of pollution which has caused great harm to human health, food shortages, increased social inequalities, among many other effects catastrophic environmental problems; the natural sciences have played an important role in raising awareness of the ill effects of ending human behaviors related to the environment. This article aims to discuss the environmental crisis and its impact on this way through a critical approach to understand the biology role in promoting environmental education. Thus, beyond the mere teaching of the components conservation practices of flora and fauna, biology education needs to present a character criticality when faced with problems enabling students to understand the complexity of environmental problems and their extent and their global effects.

Keywords: Environmental Issues. Biology teaching. Environmental Education. Critical approach. 


\section{Introdução}

Os casos cada vez mais alarmantes de destruição dos recursos naturais, de espécies animais e vegetais em extinção, de catástrofes naturais, de problemas ligados à poluição como o aquecimento global, ocupam os noticiários diariamente e promovem discussões em todo o mundo. Hoje vivemos o que pode ser percebido como crise ambiental, crise ecológica, problemática ambiental (Guimarães, 2000) ou então, para uma abordagem crítica desse fenômeno, considerando os fatores sociais e econômicos da crise, pode-se simplesmente dizer que estamos vivenciando uma crise da civilização. Essa afirmação sustenta-se em Leff (2010b), pois para ele: “A problemática ambiental a poluição e a degradação do meio, a crise de recursos naturais, energéticos e de alimentos - surgiu nas últimas décadas do século XX como uma crise da civilização, questionado a racionalidade econômica e tecnológica dominantes." (Leff, 2010b, p.61).

Independe da denominação do atual quadro de insustentabilidade ambiental, social e econômica, discutir e analisar a realidade atual relativa aos problemas ambientais é imprescindível para se alavancar soluções. Todas as possibilidades de análise devem ser consideradas e agregar um maior nível de seriedade e complexidade a temática em questão. Justamente essa é a proposta desse artigo de opinião: discutir a problemática ambiental relacionando-a com o modelo de organização social-econômico vigente, interrogando-se sobre o papel do ensino de Biologia na promoção da Educação Ambiental através de uma abordagem crítica.

Assim, esse artigo apresenta-se organizado em dois temas principais: "O atual cenário da crise ambiental e suas diferentes abordagens" e "O ensino de Biologia e a Educação Ambiental".

Na primeira seção, o artigo apresenta dados que evidenciam a existência da crise ambiental, os eventos mundiais dela decorrentes e as implicações desses eventos para a educação ambiental em nível mundial. Além disso, essa primeira parte trata das diferentes abordagens da crise ambiental em três subtemas: "A abordagem da ecologia radical"; "A abordagem do ambientalismo moderado" e "A abordagem da ecologia política".

Por sua vez, a segunda seção "O ensino de Biologia e a Educação Ambiental" discute a importância da apreensão dos conceitos relativos às ciências naturais e sua relação com a Educação Ambiental; incita a discussão, em bases críticas, dos objetivos do ensino de Biologia; propõe uma nova abordagem dos conteúdos de Biologia; do papel do professor na construção da consciência ecológica e da ciência no entendimento da complexa relação homem-homem, homem-ambiente e sociedade-natureza.

Finalizando, as conclusões vão, na medida em que revisam as principais ideias defendidas nesse artigo, resultado de um esforço teórico com o objetivo de compreender a problemática ambiental através de um olhar crítico e reflexivo, questionar o atual modelo de civilização convocando o leitor para, mediados pelo diálogo de saberes (Leff, 2001) e pelo pensar complexo (Moran, 2002), trilharmos um novo caminho rumo à sustentabilidade. 


\section{$2 \mathrm{O}$ atual cenário da crise ambiental e suas diferentes abordagens}

Os efeitos da problemática ambiental estão se tornando cada vez mais visíveis e, portanto, torna-se também visível a preocupação em torno do futuro do planeta e de todos os seus habitantes. Pesquisadores das diversas áreas da ciência discutem os efeitos causados pela ação antrópica ao longo de todo o processo civilizatório. Muitos estudos atribuem ao homem, através dos processos da construção de sua existência cultural, social e econômica apropriando-se dos recursos naturais, a responsabilidade pelos problemas ambientais que hoje se configuram. Para Miller Jr. (2013, p.12) as principais causas dos problemas ambientais são: “crescimento populacional, desperdício de recursos, pobreza, falta de responsabilidade ambiental e ignorância ecológica", dentre tantas outras ações humanas que estão diretamente ligadas aos problemas ambientais.

Dados estatísticos confirmam que nunca antes na história da humanidade houve um crescimento tão significativo no número de habitantes no mundo. A população mundial cresceu espantosamente e hoje já somos mais de 7,2 bilhões de pessoas a habitar o planeta. O crescimento apresentou maior expressão entre 1950 e 2005, onde o crescimento exponencial foi de 4 bilhões de pessoas, passando de 2,5 bilhões para 6,5 bilhões. Tais constatações estão na base das discussões acerca da capacidade de suporte da população (Hogan, 1993).

De acordo com o crescimento exponencial a população mundial tenderá a crescer ainda mais, pois quanto maior o número atual de habitantes no mundo, maior será o número de habitantes no futuro, pois os números atuais crescerão exponencialmente. Caso não ocorra algo que mude essa realidade como, por exemplo, um crescimento significativo nos índices de mortalidade, a previsão é de que até o fim desse século a população mundial alcance a casa dos 8 a 10 bilhões de pessoas (Miller, 2013).

A preocupação latente a esse crescimento diz respeito à utilização dos recursos naturais do planeta. Sabendo-se que a população mundial apresenta-se dividida entre pobres e ricos, habitantes de países desenvolvidos e em desenvolvimento, podem-se questionar quais dessas populações mundiais estaria causando maiores danos à natureza. Algumas pesquisas relacionam o avanço da crise ambiental aos altos índices de consumo por parte dos que possuem maior poder aquisitivo.

Jacobi afirma que:

Assim, o que se observa é que, enquanto se agravavam os problemas sociais e se aprofunda a distância entre os países pobres e os industrializados, emergiram com mais impacto diversas manifestações da crise ambiental, que se relacionam diretamente com os padrões produtivos e de consumo prevalecentes. (Jacobi, 2003, p. 177).

O que se pode inferir de antemão, sobre essa afirmativa, relaciona-se à busca de solução dos problemas ambientais já existentes, ocasionados pela ação antrópica, e que para se evitar outros ainda maiores, se faz necessária a criação de uma relação sustentável entre sociedade de consumo e natureza.

O cenário degradante da problemática ambiental pode também ser delineado pela destruição sem precedentes dos recursos naturais ao longo do processo civilizatório. Para Odum \& Barrett (2007, p. 03) a "civilização começou, de fato, quando o homem aprendeu a servir-se do fogo e de outros instrumentos para modificar o seu ambiente". Desde o surgimento do homem a natureza passou a ser fonte de exploração inicialmente pelos grupos humanos nômades, e mais tarde pelo homem sedentário. 
Esse último desenvolve a agricultura de subsistência e passa a controlar a produção de alimentos pelo cultivo de algumas espécies vegetais e a domesticação de alguns animais que lhe serviam de alimento e auxiliavam no trabalho agrícola. Assim conclui-se que desde os primórdios, na relação homem-natureza, fica evidenciado que o homem coloca-se como dominador e a natureza como um ente dominado.

Porém, há que se levar em conta que durante todo o processo de dominação da natureza pelo homem, existiram agruras e infortúnios ligados ao desconhecimento do funcionamento da natureza pelo homem, que muitas vezes via-se obrigado a migrar para outras regiões do planeta visto não conseguir produzir sua existência dado as constantes modificações climáticas nas áreas por ele habitadas. E em que tudo isso resultou? Mazoyer e Roudart (2010, p.46) resumem: "Milênios de evoluções isoladas, às vezes entrecruzadas, produziram, dessa maneira, toda uma gama de sistemas agrários fundamentalmente distintos e com desempenho muito desigual, que ocupam os diversos meios exploráveis do planeta". Essa diversidade de sistemas agrários dá-se também pela engenhosidade humana em se utilizar da natureza no que ela tem de melhor para oferecer, garantindo assim sua sobrevivência.

Para produzir alimentos sempre em maior escala devido às exigências do aumento populacional e do sistema capitalista de produção, os recursos naturais estão sendo levados a exaurirem-se. E diante do atual quadro de destruição da natureza, temos três tipos preponderantes de visões, Jatobá et al. (2009) vai denominá-las: a abordagem da ecologia radical, a abordagem do ambientalismo moderado e a abordagem da ecologia política.

\subsection{A abordagem da ecologia radical}

A abordagem da ecologia radical apresenta as seguintes visões: biocêntrica, ecológica e territorial. O que existe de semelhante em cada uma delas é a preocupação em discutir a crise ambiental tendo como centro a natureza. Assinala-se que os ganhos relativos à construção de propostas de solução para os problemas ambientais, decorridos dos movimentos baseados na ecologia radical, foram inúmeros, sendo os principais, na visão de Jatobá et al. (2009): à criação de reservas naturais, o combate à caça indiscriminada protegendo assim a vida dos animais selvagens, a criação de muitas instituições internacionais de proteção dos recursos naturais e controle da poluição do meio ambiente. Tais preocupações com a natureza foram oficializadas através de muitas leis ambientais que, a exemplo dos Estados Unidos que em 1970 cria a Lei Nacional de Política Ambiental Norte-Americana (National Environmental Policy Act), no Brasil é criado em 1973 a Secretaria Especial de Meio Ambiente (Sema).

Pode-se inferir através do que foi demonstrado pelo texto que a abordagem da ecologia radical apresenta muitos ganhos, porém, também se constata algumas falhas que segundo Jatobá et al. (2009) podem ser assim entendidas:

As políticas da ecologia radical foram importantes para a construção de uma consciência ecológica. Elas são fundamentais para o entendimento dos processos ecológicos e de como as atividades humanas se inserem neles e os afetam, podendo provocar desequilíbrios que se refletem em ameaças à própria sobrevivência humana. No entanto, a sua ênfase nas questões ecológicas dificulta, por um lado, a conciliação de suas propostas com objetivos econômicos e, por outro lado, com demandas sociais (Jatobá et al., 2009, p.07). 
O radicalismo da abordagem ecológica não abre possibilidades para os países subdesenvolvidos crescerem economicamente uma vez que a mesma traduz os interesses dos países ricos filiados à proposta de crescimento zero do Tratado de Meadows (1972). Além disso, essa abordagem não considera a importância da intervenção humana na constituição dos problemas atuais, tanto como responsável pelos problemas ambientais, quanto a buscar soluções para esses.

\subsection{A abordagem do ambientalismo moderado}

Em contraposição ao radicalismo ecológico, segundo Jatobá et al. (2009) tem-se o ambientalismo moderado. O mesmo surgiu a partir da década de 70 e refletiu a preocupação com o esgotamento dos recursos naturais. Nessa mesma época ocorreu a Conferência de Estocolmo que também veio assinalar a preocupação em torno dos problemas ambientais gerados pelo sistema capitalista e a preocupação de que as futuras gerações estariam sendo ameaçadas. Jatobá et al. (2009) descrevem o cenário de surgimento do ambientalismo moderado:

[...] partia de uma preocupação com os níveis de produção e consumo e chegava à conclusão de que a sua continuidade acarretaria, em poucos anos, uma crise econômica sem precedentes e que a própria vida na Terra estaria em perigo de extinção. O alerta ensejou a realização da primeira Conferência das Nações Unidas sobre o Meio Ambiente, em Estocolmo em 1972. Naquele mesmo ano foi criado o Programa das Nações Unidas para o Meio Ambiente (Pnuma) (Jatobá et al., 2009, p.08).

O ambientalismo moderado oferece aos países subdesenvolvidos a possibilidade de se desenvolver economicamente. O desenvolvimento econômico deixa de ser visto como uma ameaça ao meio ambiente, mas sim necessário ao combate à pobreza. Então a Comissão Mundial sobre Meio Ambiente e Desenvolvimento - CMMAD - criada pela Organização das Nações Unidas - ONU - em 1983 elabora o Relatório da Comissão Brundtland, de 1987, também chamado em inglês de Our Common Future, que oficializa o termo desenvolvimento sustentável, colocando fim a visão ecocêntrica e adotando por sua vez uma atitude antropocêntrica frente à crise ambiental e as possíveis ações visando sua superação.

As informações contidas nesse relatório são produto de três anos de pesquisa da comissão que foi presidida pela norueguesa Gro Haalen Brundtland. O relatório apresenta discussões acerca da relação entre problemas ambientais e sociais na sociedade globalizada, discute o crescimento populacional, a pobreza como fator desencadeador da crise ambiental e propõe a denominação de desenvolvimento sustentável mais utilizada até os dias atuais, onde se lê que o desenvolvimento sustentável deve satisfazer as necessidades atuais das populações sem que com isso comprometa o futuro das que ainda estão por vir. (Relatório de Brundtland, 1991). Um novo entendimento de desenvolvimento passa a fundamentar as leis e as ações dos países quando o assunto é crescimento, pois este deixa de estar diretamente ligado aos fatores econômicos e passa a incluir os aspectos ambientais e sociais.

Barbieri (2011, p.19) esclarece os objetivos do desenvolvimento sustentável e os objetivos do Relatório de Brundtland ao dizer: “[...]. O objetivo da conservação, segundo esse documento, é o de manter a capacidade do planeta para sustentar o 
desenvolvimento, e este deve, por sua vez, levar em consideração a capacidade dos ecossistemas e as necessidades das futuras gerações". Trata-se de viver o presente de modo sustentável, preservar os recursos naturais do planeta garantindo assim a sobrevivência das futuras gerações.

Nessa nova abordagem da problemática ambiental, a inventividade tecnológica do homem encontrará soluções para todos os problemas causados ao meio ambiente pelo crescimento econômico adotado pelo modelo capitalista de desenvolvimento. Com essa ênfase de discussão, a conferência mundial denominada Rio 92 vem para concretizar a tendência ambientalista moderada e é tida como um dos maiores eventos sobre meio ambiente e desenvolvimento sustentável. Nesse encontro foram realizados e sistematizados acordos e leis visando controlar os danos causados pelo crescimento econômico e definir os parâmetros a serem adotados tanto pelos países desenvolvidos quanto pelos em desenvolvimento visando alcançar o desenvolvimento sustentável.

Assim, evidencia-se o caráter conciliador do ambientalismo moderado objetivando a proteção do capital natural sem que pra isso seja necessário frear o desenvolvimento econômico, segundo seus seguidores, necessário ao combate a pobreza e definidor do crescimento e desenvolvimento de uma nação. Mais uma vez citamos as conclusões de Jatobá et al. (2009) quando dizem que:

\begin{abstract}
As políticas do ambientalismo moderado tiveram o mérito de trazer à tona a discussão sobre as formas de colocar em prática as propostas da ecologia radical, sem necessariamente frear o crescimento econômico e sem alterar substancialmente o modelo de desenvolvimento vigente. O seu caráter moderador vem justamente da sua capacidade de reconhecer a pertinência e urgência dos alertas dos ecologistas radicais e, ao mesmo tempo, perceber que a moratória do crescimento seria de difícil negociação, tendo em vista os seus resultados desiguais para o mundo desenvolvido e para o mundo em desenvolvimento (Jatobá et al., 2009, p.12).
\end{abstract}

Pode-se dizer que a proposta ambientalista moderada se coloca como aliada aos países em desenvolvimento no sentido de que, moderadamente, analisa as questões ambientais e os efeitos do desenvolvimento econômico sem atribuir ao segundo a total responsabilidade pela degradação do capital natural. Claro que reconhece que o atual modelo de desenvolvimento é degradante e insustentável, mas propõe um novo tipo de desenvolvimento, este em bases sustentáveis.

\title{
2.3 A abordagem da ecologia política
}

Não se pode pensar em uma análise complexa da problemática ambiental se não forem levados em conta nessa análise que os problemas do meio ambiente são também problemas do próprio desenvolvimento. Os problemas ambientais são na verdade um reflexo das formas de consumo da sociedade capitalista. Guimarães (2001, p.51) afirma que: "A compreensão adequada da crise pressupõe, portanto, que esta diz respeito ao esgotamento de um estilo de desenvolvimento ecologicamente depredador, socialmente perverso, politicamente injusto, culturalmente alienado e eticamente repulsivo". Tratase do preço a ser pago pelo modo de vida consumista e inconsequente que infelizmente é tido como padrão de felicidade para a atual sociedade de consumo.

Assim, para a abordagem da ecologia política existe uma relação direta entre os seres humanos e sua forma de organização social, política e econômica e os problemas 
ambientais. Essa abordagem inicialmente sofreu grande influência da teoria malthusiana que considerava como fator determinante dos problemas ambientais a superpopulação mundial. Para Malthus a população cresce em progressão geométrica enquanto que para os recursos naturais o crescimento ocorre em taxas aritméticas (Foster, 2005). Mais tarde, essa teoria foi contestada e uma nova abordagem da ecologia política passa a ganhar força, essa por sua vez considerando os fatores socioeconômicos e históricos na construção social dos problemas ambientais, sendo assim entendida como neomarxista.

Em resumo, sobre os objetivos e fundamentos da ecologia política, Jatobá escreve que a mesma:

[...] propõe o entendimento dos problemas ambientais a partir da análise dos contextos socioeconômicos e político ideológico relacionados aos mesmos. A ele se agrega o conceito de produção da socionatureza que nos auxilia a entender a complexidade dos fatores relacionados às questões socioambientais (Jatobá, 2006, p.12).

Assim entende-se que para os ecologistas políticos a solução para os problemas ambientais não serão obtidas através da tecnologia e que tão pouco são resultado exclusivo da má utilização da natureza pelo homem. Entende que os fatores sociais, econômicos e políticos, seja qual for o nível de abrangência que esteja sendo considerado, devem estar compondo toda e qualquer análise dos problemas ambientais.

Desse modo, pondera-se concebível, a qualquer análise sobre as abordagens da crise ambiental, muitas formas e concepções sobre as causas e os efeitos dessa. Porém mesmo não havendo consenso entre os ambientalistas com relação ao destino do planeta e dos seus habitantes, é fato aceito por todos que os altos índices de destruição da natureza vêm causando grandes males à saúde humana. Para Moran (2011):

\footnotetext{
A condição atual do nosso planeta é preocupante para aqueles que prestam atenção à evidência. Um número cada vez maior de espécies está extinta ou em extinção. As terras alagadas estão desaparecendo em velocidade acelerada, pondo em perigo as rotas de migração das aves e a manutenção da biodiversidade local e até da biodiversidade intercontinental. Níveis sem precedentes de $\mathrm{CO}_{2}$ ameaçam o sistema climático, os recifes de corais e as geleiras da Groelândia e da Antártida. Em um número crescente de cidades os níveis de poluição podem ser considerados tóxicos para a saúde humana. E a lista continua, constituindo motivos para temores consideráveis (Moran, 2011, p.29).
}

Mesmo os mais otimistas discutem a problemática ambiental considerando que a mesma se faz presente e constitui-se cada vez mais uma ameaça a todas as espécies de seres vivos do planeta. Muitos efeitos da problemática ambiental já ganham proporções catastróficas e colocam em dúvida o modelo de sociedade adotado pela grande maioria dos países do mundo e o futuro apresenta-se funesto. O exemplo disso está no relatório do economista britânico Nicolas Stern de 2006. Trata-se de um relatório encomendado pelo governo britânico com o objetivo de conhecer os índices de poluição causados pela emissão de gases geradores do efeito estufa. O relatório foi motivo de grande polêmica, pois o mesmo anuncia um futuro catastrófico para o planeta e em consequência para seus habitantes. Jatobá (2009) comenta algumas conclusões de Stern sobre os resultados das agressões impostas ao planeta pelos processos industriais e que estão descritas em seu relatório, afirmando que ele: 
[...] se deteve em calcular as perdas econômicas e as conseqüências sociais das mudanças climáticas. Ele afirma que elevações da temperatura entre $1^{\circ} \mathrm{C}$ e $5^{\circ} \mathrm{C}$ poderão acarretar secas, inundações, desabastecimento de água, redução de safras agrícolas, desnutrição, fome, exposição a doenças e extinção de espécies. Essas alterações afetarão preponderantemente populações mais vulneráveis nas regiões pobres do mundo (Jatobá et al., 2009, p.19).

Como vemos as alterações climáticas que hoje se apresentam, anunciam catástrofes ambientais sem precedentes, escassez de alimentos, doenças, extinção de espécies, aumento das desigualdades sociais e morte. Cavalcanti (2004) assinala os perigos ao meio ambiente que são ditados pela soberania do consumidor:

É aqui que um esforço de entendimento da realidade toma corpo quanto aos perigos de danos irreversíveis ao meio ambiente, quanto ao inevitável esgotamento de recursos finitos, quanto à necessidade de enfrentamento da questão da tecnologia e do seu livre uso pelas empresas, quanto à avaliação dos padrões de consumo/desperdício insustentáveis apoiados no conceito da soberania do consumidor (Cavalcanti, 2004, p.151).

Ante tais prospectivas para o futuro de nosso planeta, nossa casa, investiga-se a contribuição do ensino de biologia visando conter o avanço dos efeitos da crise ambiental possibilitando a construção de novos comportamentos frente à utilização dos recursos naturais, o desenvolvimento da consciência ecológica e a criação de modos de vida sustentáveis.

\section{O ensino de Biologia e a Educação Ambiental}

Toda e qualquer mudança de comportamento por parte de qualquer ser vivo é antecipada por um aprendizado novo. Entende-se que somente se extingue um comportamento quando se aprende que ele é considerado ruim ou nocivo à vida. Eis o papel do conhecimento nesse processo e em se tratando de conhecimentos específicos como o caso dos que se refere ao meio ambiente; o ensino de biologia é fundamental nos processo de construção de novos comportamentos relativos à natureza.

Nesse sentido, Araújo e Bizzo (2005) assinalam a importância do conhecimento na formação da consciência ambiental:

Acredita-se que é através do conhecimento que o indivíduo consciente muda sua forma de se relacionar com o meio, de maneira a conservar os bens naturais para as gerações futuras e a transformar os construtos ambientais, historicamente elaborados pelo homem em uma sociedade mais justa (Araújo \& Bizzo, 2005, p.01).

As mudanças nas formas de se relacionar com o meio ambiente necessitam do aprendizado de conceitos científicos relativos ao funcionamento da natureza e sobre as consequências maléficas das ações antrópicas impressas ao meio ambiente desde o surgimento do homem com sua forma de organização social e econômica. Em se tratando de ensino, são esses conceitos que, uma vez adquiridos pelo professor, se farão presentes no momento de conduzir sua aula visando contribuir significativamente para a construção de uma relação sustentável entre sujeito e meio ambiente.

Para Oliveira et al. (2007, p.473): “A apreensão dos conceitos básicos de ciência e a consciência das possíveis consequências que tal conhecimento produz requerem a formação de um profissional qualificado e comprometido com o processo educacional". Estar qualificado para contribuir com a construção da consciência ecológica do aluno 
exige do profissional da educação um conhecimento amplo e complexo de conceitos ligados à área das ciências biológicas.

Esse saber complexo não admite mais o pensar a natureza desvinculada do homem, acreditando que a mesma independe da vontade e das ações desse para continuar seu ciclo de vida. A solução da problemática ambiental requer bem mais que um conjunto de atitudes preservacionistas, requer o entendimento de que o homem e a natureza estão interligados e que a relação que se estabelece entre esses dois agentes é imprescindível para a existência e sobrevivência de ambos.

Sobre a relação de interdependência entre o homem e a natureza Marx (1844) escreveu em seu Primeiro Manuscrito Econômico-Filosófico: “A afirmação de que a vida física e mental do homem e a natureza são interdependentes, simplesmente significa ser a natureza interdependente consigo mesma, pois o homem é parte dela". Uma abordagem crítica da relação entre o homem e o ambiente natural abarca a complexidade das discussões sobre o atual quadro de degradação ambiental - acessível e é amplamente divulgado através das pesquisas que são realizadas por biólogos e outros pesquisadores ligados às ciências naturais - relacionando-o diretamente às ações antrópicas. Tal pensar complexo sobre as relações sociedade e natureza, homem e ambiente natural, permite também antever o futuro do planeta se a humanidade continuar a adotar o atual estilo de vida consumista ditado pelo modelo capitalista neoliberal de economia.

Foladori e Taks (2004) ampliam essa discussão ao afirmarem que:

O conceito de natureza, que exclui as relações entre os seres humanos, faz com que os problemas ambientais apareçam como comuns à espécie humana, sem considerar que as próprias relações e contradições no interior da sociedade humana são, elas também, naturais. A definição do que é natureza - delimitação básica para a ação técnica sobre o ambiente depende dos conflitos sociais e do poder ideológico (Foladori e Taks, 2004, p.332).

Quando o ensino de Biologia acontece tendo como base de entendimento da problemática ambiental apenas os males que vem sendo causados à natureza ao longo do processo civilizatório, desvinculando o homem do meio natural, colocando-o em um patamar de superioridade em relação aos seus semelhantes e aos demais elementos naturais, tem-se a formação de um conceito superficial sobre essa temática. Acselrad, Mello e Bezerra (2009) em seu livro O que é justiça ambiental escrevem: "Por muito tempo o poder sobre os homens foi condição do poder sobre o território e seus recursos" (Acselrad, Mello e Bezerra, 2009, p.120). Essa visão poderá produzir pensamentos errôneos sobre a relação sociedade e natureza fazendo com que alguns estudantes cheguem a acreditar que a natureza é um ente a serviço do homem propagando a visão antropocêntrica que já se mostrou insustentável para a relação homem e meio ambiente desde o período colonialista.

Os Parâmetros Curriculares Nacionais, em seu caderno Ciências Naturais, também apresenta uma discussão semelhante:

Durante muitos séculos, o ser humano se imaginou no centro do Universo, com a natureza à sua disposição, e apropriou-se de seus processos, alterou seus ciclos, redefiniu seus espaços, mas acabou deparando-se com uma crise ambiental que coloca em risco a vida do planeta, inclusive a humana (BRASIL, 1998, p.22). 
Ante essa problemática, as ciências naturais desempenham um importante papel para a discussão da crise ambiental e para a efetivação da Educação Ambiental. Através delas é possível conhecer o funcionamento da natureza, as inter-relações que são estabelecidas entre os ecossistemas e os modos pelos quais as ações antrópicas podem afetar prejudicialmente o equilíbrio dos biomas. Cabe também ao conhecimento científico relativo ao ambiente natural, mobilizar a criação de projetos para solucionar os muitos problemas ambientais já existentes e que carecem de intervenções imediatas. Esse novo olhar sobre o papel da ciência, aproximando-a das questões sociais é apresentado por Leff (2010a) quando diz que:

Teremos que aprender o que a ciência pode saber sobre o aquecimento global e o grau e formas de risco para a humanidade e para as populações locais; será preciso conhecer as relações entre o processo econômico e a degradação ambiental, o vínculo entre a lei do mercado e a lei da entropia. Mas também teremos de aprender a construir uma nova racionalidade social e produtiva. Temos de aprender não apenas com a ciência, mas também com os saberes dos outros; aprender a ouvir o outro; aprender a nos sustentar em nossos saberes incompletos, na incerteza e no risco; mas também na pulsão do saber (Leff, 2010a, p.184).

Durante muitos séculos a ciência permaneceu intocável por seu empirismo e pragmatismos irrefutáveis, ocupando um patamar superior em relação às demais áreas do conhecimento humano. Porém, a crise civilizatória demonstrou que para muito além de identificar os problemas ambientas e os riscos que esses impõem a vida dos seres que habitam o planeta, se faz necessário o diálogo de saberes. Para Leff (2001, p. 179): "os conflitos ecológicos e a crise ambiental não podem ser resolvidos mediante uma administração científica da natureza". Faz-se necessário incluir os muitos saberes existentes, estabelecer uma ponte entre os conhecimentos científicos sobre o ambiente e os saberes vivenciados pelo homem, muitos deles produzidos pela cultura, portanto saberes oriundos do contato direto entre homem e natureza.

Uma abordagem crítica do ensino de Biologia preocupa-se em trabalhar os conteúdos indispensáveis à compreensão dos elementos constituintes dos ecossistemas: como estes se estruturam, como se relacionam e interdependem uns dos outros, como as ações antrópicas podem afetá-los. Porém, além de munir os estudantes dos conceitos científicos específicos da Biologia, a abordagem crítica capacitará os alunos a realizar a ação do pensar complexo sobre relação homem-ambiente natural, refutando qualquer hierarquia de agentes, percebendo a interdependência entre todos os seres do planeta e de como tal interdependência é responsável pela existência de muitas entropias.

Araújo e Bizzo (2005) discutem as atuais formas de inserção da problemática ambiental em sala de aula e propõem novas possibilidades de formação docente através de uma abordagem crítica da crise ambiental:

Portanto, no contexto de sala de aula, não se pode inserir a problemática ambiental exclusivamente como derivação do aproveitamento dos recursos naturais, redução da poluição etc., mas, também, das transformações sociais que historicamente vêm sendo construídas e da conduta social que o momento exige. Portanto, para alcançar os efeitos na educação básica, é necessário inserir na formação inicial dos professores a questão ambiental a partir da contradição instituída entre o modelo de desenvolvimento civilizatório adotado pelo ser humano, diante do fascínio do mundo industrializado, e a sustentabilidade por parte dos ecossistemas para esse tipo de desenvolvimento (Araújo \& Bizzo, 2005, p.02). 
Já por muitas décadas, as discussões sobre a utilização dos recursos naturais pelo homem, vêm sendo alvo da preocupação dos professores. Em nome disso, projetos de educação ambiental compõem anualmente os planejamentos de ensino. Resultam em ações que visam conscientizar os alunos ao uso correto da água, ao destino correto do lixo, incentivam a reciclagem e economia de bens que utilizam em sua fabricação recursos naturais findáveis, como por exemplo, a luz elétrica ou utensílios fabricados a partir de petróleo. Outros, não sabedores de que hoje a maioria do papel produzido origina-se de reflorestamento de Pinus e/ou Eucalipto, encorajam a economia de papel acreditando que seu desperdício pode gerar desmatamento e por isso, também incentivam o plantio de árvores nativas e visitação a parques e reservas ambientais visando à conscientização ecológica.

Essas e muitas outras ações ambientais já são realidade nas escolas, mas é possível e necessário ampliar a visão da problemática ambiental, compreendê-la como resultado do atual modelo de civilização para então questionar as ações do homem em âmbito local e global que estão contribuindo para a insustentabilidade da vida no planeta. Professores cuja visão da crise ecológica foi ampliada através de reflexões críticas dos fenômenos dela constituintes, na visão de Guimarães (2000),

\begin{abstract}
[...] Terão presentes em suas práticas pedagógicas categorias como igualdade, solidariedade, participação crítica, que no seu exercício antagonizam-se com o princípio excludente do projeto dominante. Tal práxis pedagógica, como dimensão educativa da ação política, constituir-se-á como uma ação criativa sobre as relações de dominação vigentes nesse modelo de sociedade, produtora da miséria social, em um maior espectro, da miséria ambiental responsável pela crise ecológica planetária da atualidade (Guimarães, 2000, p.70).
\end{abstract}

Ao projeto dominante de sociedade, o homem é um ser cuja função é buscar a auto realização não importando a quais custos. Dominar a natureza e seu semelhante é um dos conceitos fundamentais ao projeto da atual civilização e seu modelo capitalista de organização. Cumpre ao ensino de ciências naturais, questionar esse modelo de civilização através do conhecimento que se tem sobre os efeitos maléficos desse para a natureza. Ampliar a discussão do uso insustentável dos recursos naturais atrelado ao modelo de consumo da atual sociedade. Incluir em sua proposta de ensino, os valores citados por Guimarães (2000, p. 70): "igualdade, solidariedade, participação crítica", compreendendo que os mesmos são indispensáveis à preservação da natureza e, por conseguinte, do próprio homem.

\title{
4 Conclusões
}

Como visto a realidade que se apresenta quanto aos efeitos da problemática ambiental já mobilizou eventos mundiais, e cada vez mais vem impulsionando pesquisas e políticas públicas que objetivam evitar danos ainda maiores aos ecossistemas, danos esses decorrentes da relação sociedade e natureza. O homem está tomando consciência de que da sua forma de se relacionar com o ambiente, seja ele social ou natural, depende o futuro do planeta.

Ao longo das muitas décadas de discussão sobre os efeitos destrutivos da relação homem e natureza, muitas abordagens de análise da crise ambiental foram desenvolvidas e, ao seu tempo, cada uma delas trouxe respostas e apontou caminhos de 
superação para a crise. Mas a sociedade é dinâmica e o conhecimento é provisório e tende sempre a ser superado por novos saberes. Sendo assim, as diferentes formas de analisar os problemas ambientais vão sendo substituídas por abordagens mais complexas. Cada vez mais vem sendo reconhecida a existência de uma crise dos modelos de sociedade vigentes. As novas formas de entender a crise ambiental vão concebê-la como uma crise socioambiental, pois não se permite no pensamento complexo, a separação paradigmática entre natureza e sociedade. Do mesmo modo que não se concebe estudar as manifestações da crise ambiental sem relacioná-las às formas de organização social em todos os âmbitos: social, econômico, político e cultural.

Sendo assim, um novo modo de condução do ensino de Biologia vem sendo proposto pelas atuais pesquisas nessa área. Conclui-se que para além do ensino de conteúdos preservacionistas e ambientalistas, o papel da Biologia é alavancar discussões que possibilitem ao aluno pensar de modo complexo a problemática ambiental. Munindo-o dos saberes necessário à compreensão da crise, não apenas em seus aspectos naturais, mas incluindo nessa análise os fatores sociais, econômicos, políticos e culturais, percebendo tratar-se de uma crise socioambiental, produto do atual modelo socioeconômico de relação sociedade-natureza.

\section{Referências}

ACSELRAD, H; MELLO, C. C.A; BEZERRA, G. N. O que é justiça ambiental. Rio de Janeiro: Garamond, 2009.

ARAUJO, M.I.O.; BIZZO, N. O discurso da sustentabilidade, educação ambiental e a formação de professores de Biologia. Enseñanza de Las Ciencias. 2005; Número extra. VII Congreso: 1-5.

BARBIERI, J.C. Desenvolvimento e Meio Ambiente: as estratégias de mudanças da agenda 21. 12 ed. Petrópolis: Vozes; 2011, p. 9-41.

BRASIL. Secretaria de Educação Fundamental. Parâmetros curriculares nacionais: Ciências Naturais / Secretaria de Educação Fundamental. Brasília: MEC / SEF, 1998.

CAVALCANTI, C. Uma tentativa de caraterização da economia ecológica. Ambiente \& Sociedade. 2004; 149-158. Disponível em $<$ http://www.scielo.br/scielo.php?script=sci_arttext\&pid=S1414753X2004000100009 \&lng=pt\&nrm=iso $>$. Acesso em 29 de março de 2015.

FOLADORI, G.; TAKS, J. Um olhar antropológico sobre a questão ambiental. Revista Mana. $\quad 2004 ; \quad 10 \quad$ (2): 323-348. Disponível em < http://www.scielo.br/scielo.php?script=sci_arttext\&pid=S010493132004000200004>. Acesso em 01 de maio de 2015.

FOSTER, J. B. A ecologia de Marx: materialismo e natureza. Rio de Janeiro: Civilização Brasileira, 2005. 
GUIMARÃES, M. Educação Ambiental: no consenso um embate? 5ª ed. São Paulo: Papirus, 2000.

GUIMARÃES, M. A formação de educadores ambientais. 8 ed. Campinas: Papirus, 2012.

GUIMARÃES, Roberto. "A ética da sustentabilidade e a formulação de políticas de desenvolvimento" In: VIANA, G; SILVA, MARINA; DINIZ, N. (orgs). O desafio da sustentabilidade: um debate socioambiental no Brasil. São Paulo: Editora Fundação Perseu Abramo, 2001. p: 43 a 68.

HOGAN, D. J. Crescimento populacional e desenvolvimento sustentável. Lua Nova, Revista de Cultura e Política. 1993; n. 31. Disponível em < http://www.scielo.br/scielo.php?pid=S0102-64451993000300004>. Acesso em 04 de maio de 2015.

JACOBI, P. Educação ambiental, cidadania e sustentabilidade. Cadernos de Pesquisa, n. 118: 189-205. Março/ 2003. Em <http://www.scielo.br/pdf/cp/n118/16834.pdf.> Acesso em: 26 de março de 2015.

JATOBÁ, S. U. S. Gestão do território e a produção da socionatureza nas ilhas do lago de Tucuruí na Amazônia brasileira. 2006. 301 f. Tese. (Doutorado em Desenvolvimento Sustentável). Centro de Desenvolvimento Sustentável, Universidade de Brasília, Brasília, DF: 2006.

JATOBÁ. S. U. S.; CIDADE, L. C. F.; VARGAS, G. M. Ecologismo, Ambientalismo e Ecologia Política: diferentes visões da sustentabilidade e do território. Sociedade e Estado, Brasília, v. 24, n. 1, p. 47-87, 2009.

LEFF. E. Saber Ambiental. Petrópolis: Vozes, 2001.

LEFF, E. Discursos sustentáveis. São Paulo: Cortez, 2010 a.

LEFF, E. Epistemologia ambiental. 5ª ed. São Paulo: Cortez, 2010b.

MARX, K. Manuscritos Econômico-Filosóficos. 1844. Disponível em $<$ https://www.marxists.org/portugues/marx/1844/manuscritos/prefacio.htm>. Acesso em 29 de março de 2015.

MAZOYER, M., ROUDART, L. História das agriculturas no mundo: do neolítico à crise contemporânea [tradução de Cláudia F. Falluh Balduino Ferreira]. - São Paulo: Editora UNESP; Brasília, DF: NEAD, 2010.

MEADOWS, D. and Meadows, D. The Limits to Growth: A Report for the Club of Rome's Project on the Predicament of Mankind. New York: Universe Books, 1972.

MILLER JR., G. T. Ciência Ambiental. 11ª edição. São Paulo: Ceangage Learning, 2013. 
MORAN, E. Ciência com consciência. Rio de Janeiro, Bertrand Brasil, 2002.

MORAN, E. F. Meio ambiente e ciências sociais: interações homem-ambiente e sustentabilidade. São Paulo: Editora SENAC, 2011.307p.

ODUM, E. P.; BARRETT, G. W. Fundamentos de ecologia. São Paulo, SP: Cengage Learning, 2007. $612 \mathrm{p}$.

OLIVEIRA, A. et al. Educação ambiental: concepções e práticas de professores de ciências do ensino fundamental. Revista Electrónica de Enseñanza de las Ciências, 2007; 6(3): 471495. Disponível em <http://reec.uvigo.es/volumenes/volumen6/ART1_Vol6_N3.pdf>. Acesso em 04 de maio de 2015.

RELATÓRIO DE BRUNTDLAND. Nosso Futuro Comum. Comissão Mundial Sobre Meio Ambiente e Desenvolvimento. 2. ed. Rio de Janeiro: Fundação Getúlio Vargas, 1991, 430p. Disponível em <http://pt.scribd.com/doc/12906958/Relatorio-Brundtland-NossoFuturo-Comum-Em-Portugues\#scribd>. Acesso em 04 de maio de 2015.

STERN, N. Stern Review: The Economics of Climate Change; 2006. Disponível em $<$ https://www.scribd.com/fullscreen/6957968?access_key=key-1htrt9xezpcgbrpb1gj4>. Acesso em 29 de março de 2015. 